\title{
Uma análise crítica sobre os ajustes adicionais considerados nas divulgações da medida não GAAP "EBITDA ajustado" em relatórios de companhias listadas brasileiras
}

Gabriela Vasconcelos de Andrade

https://orcid.org/0000 000232901239 E-mail: gvasconcelos@usp.br

Fernando Dal Ri Murcia

https://orcid.org/0000 000222693667 E-mail: murcia@usp.br

\section{Resumo}

Objetivo: Esta pesquisa busca identificar quais são os tipos de ajustes adicionais com maior magnitude realizados via divulgações da medida não GAAP "EBITDA Ajustado" das maiores companhias listadas brasileiras e realizar uma análise sobre a adequação de tais ajustes sob uma perspectiva crítica de suas naturezas.

Método: Foram investigados em press releases de companhias do índice IBrX 100 quais os ajustes adicionais com maior magnitude realizados pelas companhias da amostra e, em seguida, realizada uma análise crítica sobre a possível utilidade ou oportunismo destes ajustes sob a ótica da teoria da Regulação e de premissas da assimetria informacional. Os períodos abrangidos pela pesquisa foram os trimestres de 2014 e 2015 .

Resultados: Os tipos de ajustes com maior magnitude são Impairment (83,34\%), Correção de erros (3,52\%), Equivalência patrimonial (1,38\%), Dividendos recebidos (1,35\%) e Provisões (1,29\%), bem como que quase $76 \%$ dos ajustes efetuados são fruto de princípios e regras contábeis.

Contribuições: As evidências do presente estudo corroboram com a posição do Iasb sobre a importância de medidas não GAAP, atualmente discutidas pelo referido órgão em ações com o intuito de melhorar o reporte financeiro, incluindo o uso de informações não GAAP em peças contábeis. Os resultados fomentam o debate sobre o tema no Brasil.

Palavras chave: Medida não GAAP; EBITDA Ajustado; Ajustes adicionais. 


\section{Introdução}

O apetite pelo tema de medidas de desempenho não GAAP é atual e promissor. Entidades profissionais e reguladoras ao redor do mundo tem se empenhado para endereçar preocupações concernentes a esse tipo de divulgação por intermédio, entre outros meios, da condução de pesquisas (Financial Reporting Council, 2013; Deloitte, 2015), da elaboração de guidances para auxiliar emissores na preparação e divulgação de métricas não contábeis (European Securities and Markets Authority, 2015; International Organization of Securities Commissions, 2016) e até da modificação de normas para incluir subtotais não GAAP em peças contábeis, como é o caso do projeto para atualização do IAS 1 (International Accounting Standards Board, n.d.a).

As referidas mensurações recebem a denominação de "não GAAP" por se tratarem de métricas que advêm de interferências manuais realizadas em números contábeis para que sejam compostos e divulgados novos números ao mercado, sendo tais interferências não permitidas pelo framework contábil tal qual é hoje concebido. Significa dizer que são medidas alternativas de mensuração de desempenho que não atendem aos Generally Accepted Accounting Principles (Nichols, Gray, \& Street, 2005), princípios esses inerentes aos demonstrativos preparados de acordo com o International Financial Reporting Standards.

Números advindos da aplicação dessas medidas estão geralmente associados a resultados ou a ganhos ajustados. Dada a variedade de conceitos e diferentes indicadores desenvolvidos a fim de apurar o desempenho das companhias, o papel de medidas não GAAP na comunicação corporativa tem sido questionado tanto pela academia (Black, \& Christensen, 2009; Cormier, Lapointe Antunes, \& Magnan, 2011; Isidro \& Marques, 2013) como por entidades contábeis (International Federation of Accountants, 2014) e firmas globais de consultoria e auditoria (PricewaterhouseCoopers, 2014; Deloitte, 2016a).

Segundo o International Financial Reporting Standards (2011), o desenvolvimento de outras metodologias pode estar atrelado ao fato de que há uma percepção no mercado de que a real performance operacional de uma empresa e seu potencial de crescimento não podem ser refletidos adequadamente por meio de uma medida única. Seguindo a lógica de tal raciocínio, existem reivindicações no mercado quanto ao uso e divulgação de métricas não contábeis com a finalidade de fornecer aos usuários medidas que permitam a avaliação da efetiva geração de caixa das companhias considerando apenas suas atividades operacionais.

Os autores acreditam que, considerando que o mercado tem procurado suprir as necessidades informacionais suas e de seus stakeholders, as normas, conforme o GAAP, podem não atender a finalidades específicas de determinados usuários, sendo imprescindível o uso e a divulgação de medidas que ultrapassem os "muros" da Contabilidade. O próprio presidente do International Accounting Standards Board se pronunciou mais de uma vez a favor de medidas não GAAP em relatórios corporativos, como quando ressaltou que "medidas não GAAP podem ser úteis para explicar diferentes aspectos do desempenho de uma empresa e não pretendemos erradicá las" (International Financial Reporting Standards, 2019).

No Brasil uma das métricas financeiras não GAAP mais utilizadas no cenário corporativo é o Earnings Before Interest, Taxes, Depreciation and Amortization (EBITDA), segundo afirma o Instituto Brasileiro de Governança Corporativa (2017). Ela apura o potencial de geração de caixa de uma companhia desconsiderando os efeitos financeiros, de impostos e da depreciação e amortização. O EBITDA Ajustado, por sua vez, vai um pouco mais além: ele considera em seu cálculo ajustes adicionais para incluir ou excluir efeitos considerados pelas empresas como não representativos de sua geração bruta de caixa (Comissão de Valores Mobiliários, 2012). Termos como "extraordinários", "não recorrentes", "não operacionais" e "não usuais" vem sendo empregados pelas empresas de forma a justificar as divulgações de medidas não GAAP.

É importante ressaltar que até o ano de 2019 não existe uma norma que regule os tipos de ajustes adicionais considerados para cálculo do EBITDA Ajustado. A ICVM n. 527 rege a divulgação voluntária do EBITDA e do Earnings Before Interest and Taxes e destaca que para o caso em que uma companhia opte por incluir outros ajustes ao EBITDA, deve haver a identificação do termo "ajustado" na divulgação (Comissão de Valores Mobiliários, 2012). 
Contudo, os tipos de ajustes efetuados pelas empresas têm sido foco de atenção por parte de entes reguladores. Young (2014) destaca que reguladores frequentemente utilizam números ajustados para monitorar as companhias e Black e Christensen (2018) afirmam que a Securities and Exchange Comission sempre se preocupou com ajustes que excluem itens que na realidade são recorrentes na demonstração de resultado, como, por exemplo, "despesas operacionais". O órgão regulador global das comissões de valores mobiliários alerta que emissores de medidas não GAAP precisam ponderar a natureza dos fatos que pretendem ser ajustados, fornecendo o devido embasamento para cada ajuste efetuado. $\mathrm{O}$ uso do Impairment, por exemplo, é considerado indevido na visão do referido órgão pelo fato de possuir em sua natureza uma suscetibilidade de repetição em um futuro previsível, não devendo ser descrito como um item "não recorrente" ou "não usual" sem haver explicações suficientes (International Organization of Securities Commissions, 2016).

A maior parte das pesquisas científicas sobre medidas não GAAP vem sendo conduzidas no cenário internacional (Black, 2016a) e, de certa forma, estão concentradas nos Estados Unidos devido ao rigor da lei Sarbanes Oxley sobre as companhias registradas na Securities and Exchange Comission no tocante à divulgação de métricas não GAAP, evitando perigos potenciais aos investidores pelo possível mau uso das mesmas. Esse argumento de mau uso de medidas não GAAP por partes das empresas é praticamente senso comum nessa linha de pesquisa, pois várias evidências anteriores sugerem esse comportamento. Graham, Harvey e Rajgopal (2005) entrevistaram mais de 400 gestores para entender os fatores que determinam as decisões de divulgação sobre ganhos e identificaram que existe uma tendência nos gestores em enfatizar medidas não GAAP quando o GAAP não é o esperado. Os resultados apontados pela pesquisa conduzida por Miller (2009), nesse mesmo sentido, sugerem que gerentes se envolvem em um comportamento de divulgação oportunístico de medidas de ganhos não GAAP, beneficiando a própria administração em detrimento dos investidores.

Em relação aos tipos de ajustes efetuados, Bradshaw e Sloan (2002) documentam que a exclusão de itens especiais, conhecidos como one time, itens transitórios e/ou não recorrentes, seria a principal diferença entre os números GAAP e os não GAAP. Evidências mais recentes indicam que o ajuste de itens não recorrentes é a forma mais comum de ajuste via medidas não GAAP, estando tais itens relacionados a fatos de reestruturações, tributos e aquisições (Black, Christensen, Ciesielski, \& Whipple, 2018b).

Já no Brasil são poucas as pesquisas no tema (Oliveira, 2018), apesar do crescente uso de medidas não GAAP em relatórios de companhias abertas (Comissão de Valores Mobiliários, 2012). Determinadas pesquisas identificaram os motivos para a utilização do EBITDA e como essa medida é utilizada pelo mercado profissional brasileiro (Momose, 2009; Carvalho, 2014; Maragno, Borba, \& Fey, 2014), outras criticam seu uso como medida capaz de garantir a cobertura de dívidas e como proxy para a geração de caixa operacional (Diaz, 2002; Frezatti \& Aguiar, 2007) ou valorizam o uso EBITDA na perspectiva do value relevance (Macedo, Machado, Murcia, \& Machado, 2012). No entanto, não foi identificada nenhuma pesquisa publicada que evidenciasse de forma crítica os tipos de ajustes adicionais considerados em medidas não GAAP para contribuir com a discussão internacional sobre os indícios da adequação ou, não, quando do uso dessas métricas.

A relevância desse estudo se justifica pelos sinais que tanto a academia, como o mercado e entes reguladores e normatizadores tem enviado em relação ao tema. Black (2016b) considera o estudo de medidas não GAAP um "tópico quente" da atualidade para a condução de pesquisas científicas. Marques (2017) pontua que evidências descritivas indicam que a divulgação dessas medidas é uma prática crescente em vários países e que as deliberações e discussões de órgãos reguladores e normatizadores faz dessa área importante para pesquisas. Essas afirmativas estão alinhadas com a percebida prevalência e recorrência de tais métricas em relatórios financeiros corporativos ao redor do mundo, em especial nas jurisdições dos Estados Unidos e Reino Unido, de onde vêm os principais movimentos regulatórios de mercado, mas também em outros países como Nova Zelândia, Austrália e França (Marques, 2017). 
Para se ter uma ideia do impacto do uso de medidas não GAAP no mercado americano, no ano de 2016, o tema "medidas não GAAP" ocupou o terceiro lugar na lista dos tópicos mais frequentemente comentados pela Division of Corporation Finance, o que levou a Securities and Exchange Comission a atualizar, nesse mesmo ano, a interpretação sobre o uso e divulgação de tais medidas para incluir novos direcionamentos às companhias que optassem por divulga las. No Reino Unido, por exemplo, das 100 maiores companhias listadas no índice FTSE no ano de 2015, 81\% delas apresentaram medidas não GAAP no início de seus relatórios anuais (Deloitte, 2016b). Conforme Black, Christensen, Ciesielski e Whipple (2018a), a proliferação de medidas não GAAP ao redor do mundo reavivou o interesse de órgãos como o International Accounting Standards Board e o Financial Accounting Standards Board no tema, os quais incluíram em suas agendas projetos voltados para a discussão e possível regulamentação de medidas não GAAP desde 2014 e 2015, respectivamente.

O objetivo do presente artigo é o de suprir uma lacuna na pesquisa contábil ao identificar quais são os tipos de ajustes adicionais com maior magnitude realizados via divulgações da medida não GAAP "EBITDA Ajustado" das maiores companhias listadas brasileiras e realizar uma análise sobre a adequação de tais ajustes sob uma perspectiva crítica de suas naturezas. A metodologia é composta por análise descritiva dos dados coletados e análises críticas sobre os resultados obtidos.

Os resultados apresentados indicam que os tipos de ajuste com maior magnitude são Impairment, Correção de erros, Equivalência patrimonial, Dividendos recebidos e Provisões, bem como que quase $76 \%$ dos ajustes efetuados pelas companhias são fruto de princípios e regras contábeis, sugerindo que companhias tem ajustado por meio de medidas não GAAP, itens que (i) não geram saída de caixa quando de suas constituições; (ii) eventos não recorrentes ou que não refletem resultados do ano sob reporte; e (iii) itens não operacionais. Esses resultados geram novas evidências no cenário corporativo brasileiro e corroboram a necessidade do uso e divulgação de medidas não GAAP, contribuindo para discussões tanto na prática como na academia contábil.

\section{Plataforma teórica}

\subsection{Uso de medidas não GAAP e teoria da regulação}

A principal problemática relacionada a divulgações voluntárias é se de fato elas garantem a qualidade do processo decisório dos usuários. A premissa comumente adotada quando o tema "medidas não GAAP" é abordado é de elas carregam consigo um viés discricionário. Há razoável consenso entre tais publicações e a disponibilização de informação enganosa: "à luz de sua prevalência e de seu potencial de serem enganosas, o uso de medidas alternativas de mensuração está cada vez mais no foco regulatório" (Deloitte, 2016b).

Uma fração considerável de evidências anteriores sugere inconsistências e oportunismo quando do reporte de medidas não GAAP (Miller, 2009; Marques, 2010; Doyle, Jennings, \& Soliman, 2013). Black e Christensen (2009), por exemplo, apontam que os gestores manipulam os ajustes realizados em ganhos não GAAP de forma a bater benchmarks estabelecidos pelas empresas. Marques (2010) sugere que gestores enfatizam métricas não GAAP quando o lucro contábil não atinge o benchmark esperado, e, no mesmo sentido, Lougee e Marquardt (2004) sugerem que companhias com prejuízo contábil estariam mais propensas a enfatizar métricas não GAAP para assim apresentar ao mercado um resultado melhorado. Em relação às exclusões consideradas em medidas não GAAP, o estudo de Doyle, Jennings e Soliman (2013) afirma que companhias que reportam exclusões estão mais propensas a bater ou superar as previsões de analistas de mercado. 
Há também pesquisas acadêmicas que apontam para a utilidade de medidas não GAAP. Essa linha de pesquisa defende que números não GAAP são mais informativos e eficientes, e que o mercado percebe ganhos "pro forma" como mais representativos dos ganhos operacionais do que os ganhos operacionais apurados conforme o GAAP (Bhattacharya, Black, Christensen, \& Larson, 2003). Bradshaw e Sloan (2002) sugerem, por exemplo, que ganhos "pro forma" são mais determinantes do que ganhos GAAP para explicar as variações nos preços das ações e que a administração das companhias tem assumido um papel proativo ao enfatizar medidas não GAAP quando do reporte corporativo.

Apesar dessas evidências, continua existindo uma forte preocupação sobre se tais medidas são confiáveis, em especial no que diz respeito ao impacto dessa confiabilidade no mercado de ações. O International Accounting Standards Board (n.d.a) afirma que inconsistências sobre o desempenho financeiro das empresas pode levar a decisões equivocadas ou insatisfatórias de investimentos, resultando em falhas de mercado e afetando as economias nacionais e globais. Malone, Tarca e Wee (2016) afirmam que ganhos não GAAP podem ser informações "barulhentas" e difíceis de interpretar, fazendo com que os investidores reajam de forma inadequada na precificação de ações.

Marques (2017) aponta que ainda que existiam evidências a favor do uso e divulgação de medidas não GAAP, os estudos anteriores parecem indicar que, apesar de poderem ser úteis ao mercado de capitais, elas têm potencial para enganar os investidores e, em especial, os "não sofisticados". O experimento efetuado pelos pesquisadores Johnson, Percy, Stevenson Clarke e Cameron (2014) considerou a disponibilização de um ganho não GAAP maior do que um ganho GAAP no relatório anual e concluiu que investidores não sofisticados, quando solicitados a identificar as medidas de rentabilidade do relatório, escolhem as informações não GAAP em detrimento das GAAPs. A pesquisa de Bhattacharya, Black, Christensen e Mergenthaler (2007) concluiu, da mesma maneira, que investidores não sofisticados confiam em informações "pro forma". Essas evidências são importantes na discussão sobre a regulação de medidas não GAAP, pois as principais regulações no mercado de capitais norte americano foram desenhadas para proteger essa classe de participantes do mercado "menos informada".

Devido ao fato de que os gestores e a Administração das companhias possuem vantagem informacional em relação aos demais participantes do mercado (Iudícibus \& Lopes, 2004), o emprego de medidas não contábeis em relatórios corporativos pode estar sendo utilizado para desviar a atenção desses participantes sobre a real situação das empresas. Além dessa premissa, há a agravante de que medidas não GAAP não são auditadas, permitindo assim uma "liberdade" na construção e apresentação desses números.

O presente estudo entende que a regulação de determinadas medidas não GAAP (as mais utilizadas globalmente) pode ser uma saída para inibir ou mitigar a possibilidade de utilização inadequada desse tipo de divulgação voluntária. Dado que há uma tendência para que medidas não GAAP apresentem números mais otimistas sobre o desempenho das companhias, é preciso que o próprio padrão IFRS forneça detalhes e a estrutura para essas divulgações (International Financial Reporting Standards, 2019).

A pesquisa de Maragno, Borba e Fey (2014) é um exemplo do benefício da regulação do EBITDA no mercado brasileiro. Ela conclui que antes de a ICVM no .527 passar a regulamentar aspectos de cálculo e divulgação do EBITDA, menos da metade das companhias do IBrX 100 estavam em conformidade com a metodologia de cálculo estabelecida. Após a regulação, $60 \%$ passou a estar em compliance com a referida metodologia, indicando um aumento na aderência aos critérios estabelecidos. Heflin e Hsu (2008) verificaram que, após a regulação sobre medidas não GAAP pela Securities and Exchange Comission, a partir de 2003, nos Estados Unidos, as companhias diminuíram a frequência e a magnitude dos ajustes ("itens especiais" e outros) efetuados via métricas não contábeis. Tais autores também identificaram que após a regulação houve um declínio na probabilidade de ganhos não GAAP divulgados baterem ou superarem as previsões dos analistas de mercado. Esses resultados sugerem que a interferência da regulação no mercado tem impactos positivos no sentido de proteger o mesmo de informações enganosas. 
Por entender os impactos positivos da regulação de medidas não GAAP, o normatizador contábil tem concentrado parte de seus esforços no projeto "Primary Financial Statements", o qual propõe alterações à Demonstração de Resultado do Exercício pelo uso de subtotais, sendo um deles fixado para todas as companhias - Earnings Before Interest and Taxes - e outro para uma diferente medida de desempenho escolhida pela administração (International Accounting Standards Board, 2018).

O referido projeto foi adicionado à agenda do Iasb em 2014 e logo em 2015 ele foi identificado como prioritário pelos respondentes, os quais indicaram que o foco do projeto deveria ser a Demonstração de Resultado do Exercício. No final de 2016, o Iasb decidiu então elaborar um projeto de melhorias a esse demonstrativo, havendo várias discussões sobre o tema e possibilidades de melhorias entre 2017 e 2019. O resultado é que, até o fim do ano de 2019, o Iasb pretende publicar um exposure draft, documento oficial que antecede uma norma contábil (International Accounting Standards Board, 2018).

A seguir está apresentada uma tabela que resume a linha do tempo do projeto e principais discussões sobre a regulamentação específica do EBITDA (International Accounting Standards Board, n.d.b).

Tabela 1

Projeto "Primary Financial Statements" e EBITDA

\begin{tabular}{|c|c|}
\hline Data & Principais Discussões e Resultados \\
\hline Julho/2017 & $\begin{array}{l}\text { Se deveria ser requerido pelo lasb a inclusão do "EBIT" como um subtotal na Demonstração de } \\
\text { Resultado do Exercício. }\end{array}$ \\
\hline Outubro/2017 & $\begin{array}{l}\text { Disponibilizado um documento denominado "Iasb Investor Update" que apresentou e discutiu, } \\
\text { dentre outros assuntos e normas, o reporte do "EBIT" como um subtotal na Demonstração de } \\
\text { Resultado do Exercício sob a perspectiva dos investidores e do próprio IASB. }\end{array}$ \\
\hline Junho/2018 & $\begin{array}{l}\text { Se o lasb deveria ou não desenvolver um guidance e/ou definir a medida "EBITDA", visto que: (i) ela é } \\
\text { amplamente utilizada por usuários das demonstrações financeiras; (ii) existem preocupações sobre } \\
\text { se ela é uma medida de desempenho válida; e (iii) há diversidade em como o EBITDA é definido e } \\
\text { calculado. }\end{array}$ \\
\hline Setembro/2018 & Nessa data o IASB ainda não havia discutido a questão levantada em Junho/2018. \\
\hline Novembro/2018 & $\begin{array}{l}\text { O lasb decidiu que o EBITDA não deveria ser incluído como um subtotal da Demonstração de } \\
\text { Resultado do Exercício e nem requerido em Notas Explicativas, por, dentre outros motivos: (i) não } \\
\text { ser aplicável a todas as entidades (comparabilidade); (ii) evitar dar proeminência a essa medida, } \\
\text { dadas as preocupações sobre a mesma é uma medida de desempenho válida; (iii) pelo fato de que } \\
\text { os usuários podem calcular essa medida se acharem que ela é útil, dado que existe o requerimento } \\
\text { de divulgar a depreciação e a amortização de maneira individual nas demonstrações financeiras; e } \\
\text { (iv) para evitar ter que descrever o que é "EBITDA". }\end{array}$ \\
\hline Dezembro/2018 & $\begin{array}{l}\text { Nessa data o lasb decidiu atender às sugestões de membros do Board sobre as discussões ocorridas } \\
\text { em novembro/2018 em relação à descrição do EBITDA, para evitar a diversidade na qual elas são } \\
\text { calculadas. Com a incorporação do termo "EBITDA" à terminologia Ifrs o lasb estaria evitando que } \\
\text { medidas divulgadas com esse rótulo fossem calculadas como "EBITDA Ajustado", bem como faria } \\
\text { com que a medida fosse comparável entre entidades. Assim, decidiu se que a descrição do EBITDA } \\
\text { seria: "operating profit before depreciation and amortisation" e que a mesma seria adicionada à lista } \\
\text { de medidas que não são consideradas medidas de performance gerenciais. Com essa abordagem, o } \\
\text { lasb estaria evitando descrever "EBITDA" e tratando a medida como um cálculo do lucro operacional } \\
\text { antes da depreciação e amortização, evitando divulgações adicionais caso ela fosse enquadrada } \\
\text { como uma medida de performance gerencial. }\end{array}$ \\
\hline Junho/2019 & Decisão pela publicação de um exposure draft até o final de 2019. \\
\hline
\end{tabular}

Fonte: elaborada pelos autores.

A cogitação em incluir medidas alternativas de desempenho no "mundo GAAP" pode ser explicada pela teoria da regulação, mais especificamente pela teoria do Interesse Público. Essa teoria sugere que quando uma regulação econômica é instituída há indícios de que uma ação foi tomada para corrigir possíveis falhas de mercado, as quais são justificadas pela ineficiência dos mercados e existência da assimetria informacional. Presume se neste caso que os incentivos do regulador são alinhados aos interesses do público e que, em função disso, ele intervém em prol do mercado (Beaver, 1998). 


\subsection{Ajustes adicionais}

A decisão sobre quais itens a administração pretende ajustar tomando por base resultados contábeis requer a aplicação de julgamento profissional e olhar crítico. Conforme pontuado pelo Instituto Brasileiro de Governança Corporativa (2017), o conselho da administração tem papel fundamental na avaliação de itens considerados "extraordinários". Apesar de as normas contábeis vigentes não permitirem que companhias divulguem na Demonstração de Resultado do Exercício uma rubrica contendo "itens extraordinários" (Comitê de Pronunciamentos Contábeis, 2011), a administração pode avaliar divulgar em seus relatórios que há fatos ocorridos sendo considerados como "não usuais" ou "infrequentes" e fazer uso de uma medida não GAAP para tal.

A Securities and Exchange Comission (2003), como consequência direta da lei Sarbanes Oxley, passou a proibir que companhias abertas americanas ajustem itens identificados como "não recorrentes", "infrequentes" e/ou "incomuns" em medidas não GAAP para suavizar seus resultados. Também há outros requerimentos importantes visando garantir a validade de tais divulgações, tais como: (i) dar proeminência à medida não GAAP diretamente comparável; (ii) fornecer detalhamento das diferenças entre a medida não GAAP divulgada e a medida GAAP diretamente comparável, estando as informações de reconciliação disponíveis ao mercado sem que haja um esforço excessivo; e (iii) fornecer uma declaração relevando as razões pelas quais a administração acredita que a divulgação de medidas não GAAP são úteis aos investidores.

O guia publicado pela European Securities and Markets Authority (2015) sobre medidas alternativas de mensuração de desempenho pontua que não é um problema por si só que elas derivem de elementos ou informações das demonstrações financeiras, mas reprova o emprego de ajustes de forma indiscriminada, não consistente e não justificada em medidas não GAAP.

Itens comumente ajustados vêm sendo combatidos por instituições competentes para tal. Ajustar o efeito do impairment contábil, por exemplo, já foi formalmente rejeitado tanto pelo International Organization of Securities Commissions (2016) como pelo presidente do órgão normatizador contábil, dada a própria natureza desse item em refletir uma despesa operacional das companhias (Deloitte, 2017). A pesquisa de Doyle, Lundholm e Soliman (2003) sugere que ajustes comumente declarados pelas companhias como "não recorrentes" e/ou "não caixa" na realidade são itens importantes para que o mercado entenda o valor futuro da firma, como, por exemplo, ajustes de perdas com operações descontinuadas e amortização do goodwill. Bowen, Davis e Matsumoto (2005), apesar de não focarem seu estudo nos ajustes em si, indicam que a partir da amostra de ganhos pro forma analisada os ajustes mais comumente realizados foram, em ordem decrescente: amortização do goodwill, despesas com remuneração baseada em ações, despesas com reestruturação e resultado com a alienação de ativos.

Por não existir até o momento um arcabouço teórico normatizado para estabelecer o que seriam itens considerados não recorrentes, não usuais ou infrequentes, existe certa abertura para que a administração das empresas se utilize desses conceitos a seu favor e também de outros termos como "não operacional" e "não caixa" como justificativa para ajustes não GAAP.

Uma questão chave para entender se as empresas têm divulgado medidas não GAAP com viés oportunístico é verificar se ela tem apresentado ajustes consistentemente. Ou seja, a empresa deve ajustar tanto a constituição como o estorno de provisões, tanto o ganho como a perda com alienação de ativos, e assim por diante. O que se tem observado, na realidade, é que as empresas têm ajustado apenas "itens negativos", fazendo com que seus números não GAAP estejam sempre melhores do que os números GAAP correspondentes: "não nos surpreende que os resultados negativos dominem os ajustes aos lucros IFRS. Devemos ser confortados quando observamos que, em qualquer ano, existem empresas que relatam um lucro não GAAP inferior ao lucro IFRS" (Deloitte, 2017, p. 6). Webber, Nichols e Street (2013) investigaram em 303 press releases de companhias americanas entre os anos de 2005 e 2010 a divulgação de medidas não GAAP de lucro e concluíram que a medida em que o lucro líquido diminui, firmas são mais propensas a sinalizarem ganhos não GAAP maiores. 
Malone et al. (2016) concluíram que, no geral, tanto empresas como analistas tendem a ajustar perdas e despesas com o efeito de aumentar os ganhos não GAAP, o que reflete em uma maior incidência de ajustes negativos em relação aos positivos. Black et al. (2018b) também identificou esse padrão ao encontrar que números não GAAP excedem tanto os números GAAP como ganhos operacionais, sugerindo que os ajustes feitos são predominantemente negativos e significantes. Uma pesquisa recente afirma que CEOs das empresas do S\&P 500 fizeram grandes ajustes para atingir ganhos não GAAP entre 2010 e 2015 e com isso receberam 23\% a mais do que a compensação anual esperada se os números utilizados fossem os GAAP (Guest, Kothari, \& Pozen, 2019).

Essas e outras evidências sugerem que as empresas normalmente ajustam apenas itens negativos por meio de medidas não GAAP, bem como para certa inadequação desses ajustes sob uma perspectiva crítica. Como forma de exemplificação de ajustes que podem ser considerados inadequados ou enganosos, inclusive pelo não compliance com os requerimentos existentes para sua apresentação ao mercado, pode ser mencionada a divulgação do "EBITDA Ajustado" da Ambev S.A. em seu relatório anual de 31/12/2015, conforme Tabela 2:

Tabela 2

Divulgação do EBITDA Ajustado da Ambev S.A. no relatório anual de 31.12.2015

\begin{tabular}{lrr}
\hline \multicolumn{1}{c}{ Reconciliação lucro líquido EBITDA R\$ milhões } & $\mathbf{2 0 1 4}$ & $\mathbf{2 0 1 5}$ \\
\hline Lucro líquido Ambev & $12.065,5$ & $12.423,8$ \\
\hline Participação dos não controladores & 296,5 & 455,4 \\
\hline Despesa com imposto de renda e contribuição social & $2.006,6$ & $3.634,2$ \\
\hline Lucro antes de impostos & $14.368,6$ & $16.513,4$ \\
\hline Participação nos resultados de coligadas e subsidiárias & $(17,4)$ & $(3,1)$ \\
\hline Resultado financeiro líquido & $1.475,4$ & $2.268,2$ \\
\hline Itens não recorrentes & 89,0 & 357,2 \\
\hline EBIT ajustado & $15.915,6$ & $19.135,7$ \\
\hline Depreciação e amortização total & $2.360,2$ & $3.074,1$ \\
\hline EBITDA ajustado & $18.275,8$ & $22.209,7$ \\
\hline
\end{tabular}

Fonte: elaborada pelos autores.

Essa divulgação foi considerada como em não conformidade com os requisitos de cálculo da ICVM n. 527 por: (i) apresentar uma linha com itens "não recorrentes" na divulgação, o que é expressamente proibido em seu artigo $3^{\circ}$; e (ii) por não divulgar o EBITDA tradicional antes do EBITDA Ajustado, de acordo com o requerido pelo inciso $1^{\circ}$ do artigo $4^{\circ}$. Adicionalmente, a divulgação não detalhou a finalidade da consideração dos ajustes adicionais "Participação dos não controladores" e "Participação nos resultados de coligadas e subsidiárias" para compor o número do EBITDA Ajustado.

A falta de compliance, de detalhamento e de clareza em divulgações de medidas não GAAP pode colaborar com a premissa de que estas mensurações são discricionárias. Uma vez que o próprio mercado possui justificativas para legitimar tais divulgações, é necessário que as companhias que optem por divulgar voluntariamente medidas não contábeis procurem assim o fazer objetivando apresentar informações fidedignas e com o devido embasamento técnico aos seus investidores e potenciais investidores, sempre respeitando as regulamentações existentes. 


\section{Metodologia}

A amostra é composta por companhias listadas presentes no índice "IBrX 100" da B3 no dia 24/2/2017, data inicial da coleta de dados. Foram selecionados os anos de 2014 e 2015 e considerados todos os períodos trimestrais (press releases) para a análise do EBITDA Ajustado, quando divulgado, totalizando 8 períodos para cada companhia da amostra. As análises foram fruto de 760 consultas a relatórios e 360 observações (relatórios que continham a divulgação do EBITDA Ajustado). Tal medida foi escolhida por ser uma das mais utilizadas no mercado corporativo brasileiro, possuir regulamentação da ICVM n ${ }^{\circ} .527$ e surgir dos ajustes adicionais realizados ao EBITDA.

A pesquisa foi assim delimitada dada a coleta manual dos dados e para considerar fatores macroeconômicos que atingiram negativamente a situação econômico financeira do Brasil nos anos entre 2010 e 2015. Conforme Malone et al. (2016), neste cenário, o mercado e a volatilidade dos preços dos ativos podem levar a uma maior sensibilidade sobre mensurações GAAP e potencialmente aumentar a utilidade de divulgações não GAAP.

Uma vez que no pregão do dia 24/2/2017 havia companhias repetidas pelo fato de possuírem mais de um tipo de ação (ON e PN) classificada como as 100 mais negociadas (como por exemplo as ações BBDC3 e BBDC4 do Banco Bradesco S.A.), foi necessário realizar um procedimento para identificar a quantidade real de companhias. O procedimento foi realizado no Excel por meio do comando "Remove Duplicates", que foi utilizado após o alinhamento dos nomes das companhias presentes no índice em apenas uma coluna. Desta forma, o Excel reconhece e exclui, automaticamente, as empresas que porventura apresentam o mesmo nome em linhas diferentes. Ao final desse procedimento, foi indicada a existência de 95 companhias.

Verificou se que do total de 95 empresas 52 empresas divulgaram o EBITDA Ajustado em pelo menos um período analisado, o que representa 55\% do total de empresas da amostra. Os dados extraídos dos relatórios trimestrais foram compilados em uma planilha Excel elaborada pelos pesquisadores. Atendendo ao objetivo apresentado na seção da introdução, as seguintes informações foram coletadas para a medida não GAAP EBITDA Ajustado: 1) tipos dos ajustes adicionais ao EBITDA; e 2) montantes dos ajustes adicionais ao EBITDA, ambos apresentados nas conciliações ao lucro (ou prejuízo) contábil, conforme requerido pela ICVM n ${ }^{\circ}$. 527. Após coletar esses dados, os pesquisadores classificaram cada ajuste em categorias que respeitaram o próprio nome dado aos ajustes, conforme divulgado pelas companhias.

A metodologia do presente estudo baseia se em análise descritiva dos ajustes adicionais efetuados via EBITDA Ajustado e, considerando os principais resultados apresentados, foram realizadas análises críticas sob a perspectiva de discussão conceitual das naturezas dos ajustes e considerando também as diretrizes e normas existentes sobre eles. Dessa forma, essa pesquisa possui natureza exploratória com base normativa, pois de acordo com Matos e Murcia (2019), se assemelha a ensaios teóricos normativos por discutir temas com base na literatura vigente, estimulando assim debates e pesquisas na linha.

Foi considerada também a perspectiva da magnitude dos itens e não somente a sua frequência, pois, conforme Young (2014), a significância econômica dos números não GAAP está baseada em parte por sua frequência e pela magnitude e natureza dos componentes excluídos por meio delas. Isso se deve pelo fato de que o impacto (distância entre a medida não GAAP e o número GAAP correspondente) será maior quando a magnitude dos ajustes for maior. Bhattacharya et al. (2003) analisam, por exemplo, a magnitude relativa entre os números GAAP e os não GAAP, relacionando isso a suas localizações nos press releases. Tal distanciamento é que tem o potencial, a princípio, de influenciar as análises de mercado dada a relevância dos ajustes efetuados. 


\section{Resultados}

\subsection{Tipos de ajustes adicionais}

Foram mapeadas um total de 37 categorias de ajustes. Os pesquisadores identificaram que cada uma delas poderia se enquadrar como sendo o reflexo de alguma norma contábil ou outro normativo. A Tabela 3 apresenta esse enquadramento, estando as categorias dispostas com base na representatividade dos montantes ajustados sobre o total ajustado (em milhões de reais e em módulo) e indicada a frequência dos ajustes (quantidade de vezes de reporte deles):

Tabela 3

\section{Categorias e montantes dos ajustes efetuados}

\begin{tabular}{|c|c|c|c|c|c|}
\hline Item & Categoria & CPCs relacionados & Montante & $\%$ & Frequência \\
\hline 1 & Impairment & CPC 01 & 146.601 & $83,34 \%$ & 25 \\
\hline 2 & Correção de erros & CPC 23 & 6.194 & $3,52 \%$ & 1 \\
\hline 3 & Equivalência patrimonial & CPC 18 & 2.436 & $1,38 \%$ & 179 \\
\hline 4 & Dividendos recebidos & Lei 6.404/86 & 2.366 & $1,35 \%$ & 8 \\
\hline 5 & Provisões & CPC 25 & 2.277 & $1,29 \%$ & 55 \\
\hline 6 & Participação de não controladores & CPC 36 & 2.232 & $1,27 \%$ & 80 \\
\hline 7 & Ativos e passivos regulatórios & Outros & 1.606 & $0,91 \%$ & 11 \\
\hline 8 & Outros (receitas e despesas) & CPC 00 & 1.580 & $0,90 \%$ & 70 \\
\hline 9 & EBITDA proporcional & Outros & 1.575 & $0,90 \%$ & 27 \\
\hline 10 & Mensuração a valor justo & CPC 46 & 1.416 & $0,81 \%$ & 38 \\
\hline 11 & Itens não recorrentes / extraordinários & Outros & 1.395 & $0,79 \%$ & 88 \\
\hline 12 & $\begin{array}{l}\text { Reestruturação, reorganização, doações } \\
\text { e indenização }\end{array}$ & Outros & 1.241 & $0,71 \%$ & 9 \\
\hline 13 & Propriedade para investimento & CPC 28 & 934 & $0,53 \%$ & 5 \\
\hline 14 & Crédito tributário / PIS e Cofins retroativo & Outros & 822 & $0,47 \%$ & 8 \\
\hline 15 & $\begin{array}{l}\text { Operações com entidades de controle } \\
\text { compartilhado }\end{array}$ & CPC 18 & 637 & $0,36 \%$ & 1 \\
\hline 16 & Resultado operacional & CPC 00 & 625 & $0,36 \%$ & 3 \\
\hline 17 & Resultado na mensuração ou venda de ativos & CPC 00 & 319 & $0,18 \%$ & 26 \\
\hline 18 & Capitalização de juros & CPC 20 & 251 & $0,14 \%$ & 8 \\
\hline 19 & Consolidação & CPC 36 & 218 & $0,12 \%$ & 6 \\
\hline 20 & Compra e pagamento baseados em ações & CPC 10 & 203 & $0,12 \%$ & 55 \\
\hline 21 & Despesas antecipadas & CPC 00 & 164 & $0,09 \%$ & 8 \\
\hline 22 & Operações descontinuadas & CPC 31 & 133 & $0,08 \%$ & 11 \\
\hline 23 & Juros e multas sobre atrasos & Outros & 124 & $0,07 \%$ & 16 \\
\hline 24 & Investimentos em companhias (participações) & CPC 18 & 99 & $0,06 \%$ & 10 \\
\hline 25 & $\begin{array}{l}\text { Resultado na alienação de participação em } \\
\text { joint ventures / coligadas }\end{array}$ & CPC 18 & 90 & $0,05 \%$ & 8 \\
\hline 26 & Despesas não caixa & CPC 00 & 72 & $0,04 \%$ & 9 \\
\hline 27 & $\begin{array}{l}\text { Arrendamento mercantil (despesa com } \\
\text { aluguéis) }\end{array}$ & CPC 06 & 65 & $0,04 \%$ & 8 \\
\hline 28 & Hedge accounting & CPC 48 & 58 & $0,03 \%$ & 12 \\
\hline 29 & $\begin{array}{l}\text { Incentivo baseado em ações sem desembolso } \\
\text { de caixa }\end{array}$ & CPC 10 & 36 & $0,02 \%$ & 8 \\
\hline 30 & Acordo comercial com fornecedores & Outros & 32 & $0,02 \%$ & 1 \\
\hline
\end{tabular}




\begin{tabular}{cllrrr}
\hline Item & \multicolumn{1}{c}{ Categoria } & CPCs relacionados & Montante & \% & Frequência \\
\hline 31 & Reversão juros sobre capital próprio & IN SRF 093/97 & 28 & $0,02 \%$ & 4 \\
\hline 32 & Receita de construção & CPC 17 & 21 & $0,01 \%$ & 6 \\
\hline 33 & Debêntures & CPC 08 & 19 & $0,01 \%$ & 8 \\
\hline 34 & Benefícios a empregados & CPC 33 & 10 & $0,01 \%$ & 8 \\
\hline 35 & Realização do custo atribuído & ICPC 10 / CPCs 27, & 10 & $0,01 \%$ & 2 \\
\hline 36 & Despesas com desligamento de pessoal & CPC 00 & 9 & $0,01 \%$ & 1 \\
\hline 37 & Despesas com M\&A & CPC 00 & 9 & $0,01 \%$ & 3 \\
\hline & Total ajustado & & 175.906 & $100 \%$ & 826 \\
\hline
\end{tabular}

Fonte: elaborada pelos autores.

Com base na Tabela 3, é possível observar que os ajustes adicionais com maior magnitude reportados nos 8(oito) períodos analisados foram, majoritariamente, Impairment e Correção de erros com, respectivamente, $83,34 \%$ e $3,52 \%$ de concentração sobre o montante total de ajustes.

Na sequência, observa se a Equivalência Patrimonial, que tanto em magnitude ( $3^{\circ}$ lugar) como em frequência ( $1^{\circ}$ lugar) se destaca, com representatividade de $21,67 \%$ do total de ajustes efetuados em quantidade de vezes de reporte. Dividendos recebidos e Provisões ocupam o $4^{\circ}$ e $5^{\circ}$ lugar com, respectivamente, $1,35 \%$ e $1,29 \%$ de concentração sobre o montante total de ajustes.

\subsection{Análise crítica sobre os ajustes adicionais}

Estudos anteriores apontam que o Impairment é um dos ajustes mais efetuados por meio de medidas não GAAP (Malone et al., 2016) e o que apresenta maior magnitude, segundo Black et al. (2018b). Dessa forma, os achados desse estudo confirmam as evidências anteriores para a frequência e a relevância desse ajuste.

O Impairment nada mais é que o reconhecimento do efeito econômico de uma perda nas demonstrações financeiras por desvalorização de ativos sob o escopo do CPC 01 (R1) Redução ao Valor Recuperável de Ativos. No mínimo uma vez por ano as entidades necessitam avaliar se seus ativos estão registrados na contabilidade por valores que excedem os montantes a serem recuperados pelo uso ou pela venda. Esse teste visa assegurar que os montantes apresentados nas demonstrações financeiras sejam fiéis à realidade econômica dos ativos.

A contabilização desse efeito econômico é feita via resultado (com exceção de ativos que tenham sido reavaliados no passado) contra uma conta redutora do ativo a que se refere a perda. É fácil notar que não há impacto caixa nessa contabilização. A prática tem reivindicado que um dos principais motivos para uso e divulgação do "EBITDA Ajustado" seria exatamente pelo fato de que alguns itens contabilizados, segundo o GAAP, não geram saída de caixa no período de reporte e, uma vez que a companhia deseja apresentar ao mercado seu "potencial de geração bruta de caixa", itens como o Impairment, necessariamente, deveriam ser excluídos da conta. Malone et al. (2016) apontam que empresas ajustam despesas com Impairment pelo fato de que é um item que apresenta incerteza em sua mensuração, sugerindo uma possível utilidade desse ajuste, dado que ele contribui para a avaliação do desempenho atual e futuro das firmas.

Contudo, devemos ter em mente que um ativo desvalorizado e imaginando que essa perda não será revertida, em determinado momento futuro, levará a companhia a registrar uma menor entrada de caixa efetiva em função dessa desvalorização. Por exemplo: se um imobilizado que sofreu uma desvalorização de $\mathrm{R} \$ 10.000$ no momento T0 permanecer com essa desvalorização até a data da sua realização por venda no momento subsequente T1, esses $\mathrm{R} \$ 10.000$ terão, sim, impactado financeiramente o caixa da companhia, que, em período anterior desembolsou $\mathrm{X}+\mathrm{R} \$ 10.000$ para adquiri lo (custo do bem, desconsiderando a depreciação no intervalo entre T0 e T1). Olhando de maneira isolada sobre o desempenho do período de reporte T0, poderia ser útil aos investidores entender esse resultado sem o reflexo de itens não caixa; no entanto, vale salientar que esse efeito é temporal, ou seja, pode vir a se concretizar no caixa. 
Além disso, considerando os guidances existentes sobre esse tipo de ajuste e conforme já discutido no levantamento teórico, não seria adequada a exclusão do efeito do Impairment pelo fato de que ele representa uma despesa operacional para as companhias, ainda que muitas delas afirmem o contrário. Deloitte (2019) lembra que registrantes na Comissão de Valores Mobiliários americana estão proibidos pelo item 10(e) de ajustar itens como incomuns, não recorrentes ou infrequentes quando pela natureza desses itens for provável que eles ocorram novamente dentro de dois anos ou se houve um encargo ou ganho semelhante nos dois anos anteriores. Avaliando a não recorrência de um efeito contábil como um atributo para justificar a sua não operacionalidade, poderia ser possível afirmar que o Impairment é não operacional. No entanto, conforme apontam Webber et al. (2013), várias companhias ajustam o mesmo item em anos consecutivos (incluindo nessa análise o Impairment), sugerindo que, na realidade, tais ajustes ao longo do tempo estariam incorretos do ponto de vista da recorrência e/ou operacionalidade deles.

O CPC 23 Políticas Contábeis, Mudança de Estimativa e Retificação de Erros define os critérios para "para a seleção e a mudança de políticas contábeis, juntamente com o tratamento contábil e divulgação de mudança nas políticas contábeis, a mudança nas estimativas contábeis e a retificação de erro" (Comitê de Pronunciamentos Contábeis, 2009). Os erros aos quais este pronunciamento se refere, para fins de correção ou retificação, são os erros materiais, ou seja, erros que podem, individual ou coletivamente, influenciar as decisões econômicas dos usuários das demonstrações financeiras. Quando um erro material não é identificado até a publicação das demonstrações financeiras a qual ele pertence, tal erro deve ser corrigido na informação comparativa das demonstrações do período subsequente.

Não é esperado que uma companhia efetue correções de erros anteriores repetidas vezes, ou seja, trata se de um evento de natureza pontual e inclusive de um evento não desejado pelas companhias por diversas razões (a confiabilidade nos saldos das demonstrações financeiras é uma delas). Com base nisso, é possível entender que a correção de erros se trata de um evento extraordinário ou não recorrente, ou mesmo de um evento que não diz respeito ao período de reporte em questão. Isso se confirma pela observação da natureza do ajuste no montante de $\mathrm{R} \$ 6.194$ milhões indicado na Tabela 3 em relação à "correção de erros". Ele se refere a um único ajuste efetuado pela Petrobras S.A. no terceiro trimestre de 2014 para retirar o efeito da baixa de "gastos adicionais capitalizados indevidamente ao ativo imobilizado oriundos do esquema de pagamentos indevidos descoberto pelas investigações da Operação Lava Jato".

Ajustes como esse não podem representar as atividades operacionais de uma companhia, pois são advindos de fraudes e poluem o desempenho da companhia. Embora seja necessário para fins contábeis, inclusive por questões fiscais, entende se por razoável a necessidade de utilizar uma métrica não GAAP para mensurar o desempenho empresarial sem o efeito da retificação de erros.

Além dos ajustes do Impairment e Correção de erros, que juntos representam quase $87 \%$ do total ajustado, temos na sequência resultados igualmente interessantes com ajustes advindos da Equivalência Patrimonial, Dividendos Recebidos e Provisões, cada um com 1,38\%, 1,35\% e 1,29\%, respectivamente, sobre o total.

Equivalência Patrimonial é o método para reconhecimento da participação do investidor sobre os ativos líquidos de uma investida. Consoante ao CPC 18 Investimento em Coligada, em Controlada e em Empreendimento Controlado em Conjunto (Comitê de Pronunciamentos Contábeis, 2012), após um investimento ser inicialmente reconhecido pelo custo, ele é ajustado para refletir a sua participação no lucro ou prejuízo da investida em períodos posteriores. A contabilização nas demonstrações financeiras do investidor irá depender se houve uma receita ou uma despesa com equivalência patrimonial, ou seja, se a investida deu lucro ou prejuízo. Independente desse resultado, é interessante notar que o mercado justifica esse ajuste por ele não ser operacional, ou seja, ele depende do resultado das operações de outras entidades e de como elas estão sendo gerenciadas. Por isso, muitas vezes, esse resultado é excluído em medidas não GAAP, pois, fazendo isso, os emissores "isolam" o efeito das suas próprias e exclusivas operações. 
Um dado importante que corrobora isso é que das 28 empresas que efetuaram ajustes advindos de resultados com equivalência nenhuma delas é do segmento de Participações, setor que naturalmente possui como modelo de negócios ou "atividade fim" a participação em outras entidades. Esse dado é essencial para entender se os ajustes efetuados a título de equivalência patrimonial poderiam, ou não, ser considerados como itens não operacionais, o que na visão dos autores seria justificável. É preciso lembrar, no entanto, que, apesar de haver a possibilidade de que companhias classifiquem esses itens como não operacionais, eles continuam sendo itens de incidência recorrente, dado que em cada fechamento de balanço ocorrem mudanças na posição do investimento.

Por fim, o reconhecimento desse fato contábil também não impacta o caixa da companhia investidora. Conforme explicitado no exemplo da venda de um imobilizado desvalorizado, caso a companhia investidora decida se desfazer dos investimentos que possui, os efeitos que foram reconhecidos nos ativos terão efetivamente impactado o caixa. Sendo assim, não é de um todo razoável considerar que esse item se trata de um item "não caixa", pois é não caixa tão somente se for considerada a data base em que o efeito foi reconhecido.

Seguindo a mesma lógica de investimentos, os Dividendos Recebidos são valores que uma companhia recebe decorrentes de participações societárias e são lançados contra o caixa, visto que são reconhecidos em razão do seu recebimento financeiro. Ou seja, trata se de uma receita não operacional da companhia e, pelo exposto anteriormente, faria sentido que as empresas não avaliassem o seu desempenho considerando efeitos advindos de outras entidades. Também cabe aqui a discussão sobre regularidade ou frequência desses recebimentos, mas é possível que esses ajustes tenham justificativas que comprovem a necessidade de suas exclusões.

As Provisões são passivos de prazo ou de valores incertos. Segundo o CPC 25 Provisões, Passivos Contingentes e Ativos Contingentes (Comitê de Pronunciamentos Contábeis, 2009), provisões são reconhecidas como passivo porque são obrigações presentes e é provável que uma saída de recursos seja necessária para liquidar a obrigação. A contabilização de uma provisão é realizada via resultado contra uma conta passiva no circulante ou não circulante, a depender do prazo em que a obrigação levará para ser quitada. Por se tratar de contabilizações com base em estimativas contábeis, as provisões devem ser reavaliadas na data de cada balanço para refletir a melhor estimativa possível.

Percebe se que nesse caso também não há saída de recursos da entidade na data base em que a provisão é gerada; o que ocorre é o reconhecimento de um fato econômico para apresentar com fidedignidade nas demonstrações financeiras outras obrigações que a companhia possua, ainda que os valores ou prazos destas obrigações não possam ser $100 \%$ confirmados na data do reporte. Por se tratar de uma estimativa contábil que envolve julgamento e premissas subjetivas, é possível que algumas provisões ou parte delas sejam totalmente revertidas no futuro próximo em função de mudanças no cenário esperado, por exemplo.

Seguindo o mesmo racional de apresentar o potencial de geração bruta de caixa de uma entidade, as Provisões reconhecidas no período de reporte também poderiam ser alvo de ajustes ao "EBITDA Ajustado". Destaca-se que, ao considerar todas as classes de provisões no referido indicador, futuros desembolsos de caixa, caso o cenário esperado seja confirmado, também são desconsiderados, inviabilizando uma análise mais abrangente sobre se entidade espera ou não espera que essas provisões tenham impacto no caixa futuramente.

Analisando a Tabela 3, é interessante notar que das 37 categorias de ajustes apenas 9 (nove) não fazem referência direta a uma norma contábil. O resultado dessa constatação é enriquecedor e relevante, pois aponta que quase $76 \%$ dos tipos de ajustes efetuados pelas companhias são fruto de princípios e regras contábeis requeridos, mas que foram considerados pelas companhias como itens que deveriam ser excluídos ou incluídos no cálculo do EBITDA Ajustado.

De uma maneira geral, os resultados ora apresentados e discutidos estão alinhados com os resultados obtidos por Malone et al. (2016) de que empresas ajustam itens que não foram ainda realizados no período de reporte e de itens considerados não recorrentes. Apesar disso, é preciso que as empresas reflitam suas divulgações de medidas não GAAP, pois Webber et al. (2013) concluem que as justificativas para os ajustes são na realidade genéricas, não contendo conteúdo informativo por não apresentarem percepções sobre a natureza dos ajustes efetuados. 
Para os tipos de ajustes de Correção de erros, Equivalência patrimonial, Dividendos recebidos e Provisões de forma mais específica não foram encontrados resultados descritivos anteriores que pudessem ser confirmados ou não, o que pode ser explicado: (i) pela carência de pesquisas que tenham foco nas análises descritivas de medidas não GAAP; (ii) diferenças na categorização dos ajustes em cada estudo; (iii) pelas diferenças de práticas nos diferentes mercados pesquisados; (iv) por diferentes amostras e períodos investigados; e (v) porque o EBITDA Ajustado ainda não foi tão estudado em comparação com o EBITDA, por exemplo.

\section{Conclusões}

Foi possível concluir que os ajustes adicionais com maior magnitude reportados pelas companhias nos períodos analisados foram Impairment e Correção de erros com 83,34\% e 3,52\% de concentração sobre o montante total de ajustes divulgado. Na sequência, os ajustes advindos de Equivalência Patrimonial, Dividendos Recebidos e Provisões representam mais $4 \%$ sobre o total ajustado.

Apesar de os demais tipos de ajustes realizados não possuírem uma relevância em relação ao montante total ajustado, observou se que quase $76 \%$ deles é fruto do efeito de uma norma contábil nas demonstrações financeiras, como, por exemplo: Mensuração a Valor Justo, Capitalização de Juros, entre outros.

A prática tem apontado que um dos motivos para a divulgação do EBITDA Ajustado seria porque alguns itens contabilizados pelo GAAP não geram saída de caixa para as companhias: tanto o Impairment como as provisões são itens que afetam o resultado contábil, mas não geram impacto caixa quando de suas constituições, fazendo a princípio sentido que esses itens sejam desconsiderados do desempenho na visão dos preparadores.

A correção de erros, como discutido, pode ser caracterizada como um evento de natureza pontual e, portanto, é possível entendê-lo como sendo um evento não recorrente ou que não diz respeito ao período de reporte em questão. $\mathrm{O}$ resultado de equivalência patrimonial e dividendos recebidos podem não representar um resultado operacional para a investidora, pois independe de ações tomadas por ela $\mathrm{e}$ fogem ao seu controle de gestão.

Baseados nas análises críticas sobre os ajustes, os autores entendem que os resultados da pesquisa sugerem que o mercado possui reivindicações legítimas sobre a necessidade de utilizar medidas complementares aos números GAAP, mas que deve haver um cuidado nas divulgações de medidas não GAAP, buscando justificá-las conceitualmente para evitar uso discricionário. Para isso, e conforme postula a teoria da Regulação, intervenções ao mercado são necessárias quando há possíveis falhas advindas da assimetria informacional e ineficiência nos mercados. Conforme discutido ao longo do texto, pesquisas anteriores identificaram o potencial mau uso de medidas não GAAP em relatórios financeiros e de que forma esse comportamento pode impactar, negativamente, os mercados. Heflin e Hsu (2008) indicaram que as divulgações de medidas não GAAP aumentaram de qualidade após regulações, sendo esse um mecanismo para evitar problemas nas divulgações de medidas não GAAP.

Esse estudo se diferencia dos demais publicados pelo fato de ser o primeiro a analisar de forma crítica os ajustes efetuados por meio de medidas não GAAP no Brasil, tomando por base a literatura existente sobre o tema e respectivos conceitos normativos. Para os investidores, que têm o potencial de serem enganados pelo mau uso de medidas não GAAP (Marques, 2017; Black et al., 2018a), pesquisas científicas no tema podem sugerir os tipos de divulgação mais adequados, se os mercados e companhias nos quais eles investem estão atendendo às regulações e guidances disponíveis ou se evidências apontam para comportamentos oportunísticos no uso de medidas não GAAP, chamando a atenção sobre tal problemática para que possam distinguir divulgações boas das ruins em suas avalições.

Para entes reguladores, normatizadores e fiscalizadores brasileiros, essa pesquisa pode contribuir no entendimento sobre como as companhias listadas tem procedido em divulgações de uma das medidas não GAAP mais divulgadas no cenário nacional, podendo complementar a norma existente para incluir requerimentos adicionais de proteção aos investidores. 


\section{Referências}

Beaver, W. H. (1998). Financial reporting: an accounting revolution. Upper Saddle River, N.J.: Prentice Hall.

Black, D. E., \& Christensen, T. E. (2009). US managers' use of 'pro forma' adjustments to meet strategic earnings targets. Journal of Business Finance \& Accounting, 36(3 4), pp.297 326. doi: 10.1111/j.1468 5957.2009.02128.x.

Black, D. E., Christensen, T. E. (2018). Policy implications of research on non GAAP reporting. Research in Accouting Regulation, 30(1), pp.1 7. doi: 10.1016/j.racreg.2018.03.001

Black, D. E., Christensen, T. E., Ciesielski, J. T., \& Whipple, B. C. (2018a). Non GAAP reporting: evidence from academia and current practice. Journal of Business Finance \& Accounting, 45(3 4), pp.259 294. doi: $10.1111 /$ jbfa.12298.

Black, D. E., Christensen, T. E., Ciesielski, J. T., \& Whipple, B. C. (2018b). Non GAAP earnings: a consistency and comparability crisis? Tuck School of Business Working Paper No. 2759312. doi: $10.2139 /$ ssrn.2759312.

Black, E. L. (2016a). The ethical reporting of non GAAP performance measures. Revista Contabilidade \& Finanças, 27(70), pp.7 11. doi: 10.1590/1808 057x201690090.

Black, E. L. (2016b). Starting and Developing a Stream of Research. Discurso realizado pelo Prof. Dr. Ervin Black, XVI USP Internacional Conference in Accounting, São Paulo. Retirado de http://www. congressousp.fipecafi.org/.

Bhattacharya, N., Black, E. L., Christensen, T. E., \& Larson, C. R. (2003). Assessing the relative informativeness and permanence of pro forma earnings and GAAP operating earnings. Journal of Accounting \& Economics, 36(1 3), pp. 285 319. doi: 10.1016/j.jacceco.2003.06.001.

Bhattacharya, N., Black, E. L., Christensen, T. E., \& Mergenthaler, R. D. (2007). Who trades on pro forma earnings information?. The Accounting Review, 82(3), pp.581 619. doi: 10.2308/accr.2007.82.3.581.

Bradshaw, M. T., \& Sloan, R. G. (2002). GAAP versus the street: an empirical assessment of two alternative definitions of earnings. Journal of Accounting Research, 40(1), pp. 41 66. doi: 10.1111/1475 679X.00038.

Bowen, R. M., Davis, A. K., \& Matsumoto, D. A. (2005). Emphasis on pro forma versus GAAP earnings in quarterly press releases: Determinants, SEC intervention, and market reactions. The Accounting Review, 80(4), pp. 1011 1038. doi: 10.2139/ssrn.399980.

Carvalho, V. J. R. (2014). Das razões da utilização do EBITDA por profissionais de mercado: uma contribuição prática (Dissertação de Mestrado, Universidade Presbiteriana Mackenzie, São Paulo). Retirado de http://bdtd.ibict.br/vufind/Record/UPM_5713ab026e5579abc9b3179a7330ab28.

Comissão de Valores Mobiliários. CVM. (2012). Instrução CVM n. 527. Retirado de http://www.cvm.gov. br/legislacao/inst/inst527.html.

Comitê de Pronunciamentos Contábeis. CPC. (2009). Pronunciamento Técnico CPC 23 Políticas Contábeis, Mudança de Estimativa e Retificação de Erros. Retirado de http://www.cpc.org.br/CPC/ Documentos Emitidos/Pronunciamentos.

Comitê de Pronunciamentos Contábeis. CPC. (2009). Pronunciamento Técnico CPC 25 Provisões, Passivos Contingentes e Ativos Contingentes. Retirado de http://www.cpc.org.br/CPC/Documentos Emitidos/Pronunciamentos. 
Comitê de Pronunciamentos Contábeis. CPC. (2012). Pronunciamento Técnico CPC 18 Investimento em Coligada, em Controlada e em Empreendimento Controlado em Conjunto. Retirado de http:// www.cpc.org.br/CPC/Documentos Emitidos/Pronunciamentos.

Cormier, D., Lapointe Antunes, P., \& Magnan, M. (2011). Revisiting the Relevance and Reliability of Non GAAP Reporting: The Case of the Income Trusts. Contemporary Accounting Research, 28, pp.1585 1609.

Diaz, F. P. (2002). EBITDA "Uma visão crítica" (Dissertação de Mestrado, Fundação Getúlio Vargas, São Paulo). Retirado de https://bibliotecadigital.fgv.br/dspace/bitstream/ handle/10438/5742/1200202336.pdf.

Deloitte (2015). Annual report insights 2015 The reporting landscape.

Retirado de http://www.iasplus.com/en/publications/uk/other/annual report insights 2015.

Deloitte (2016a). Heads up: Top 10 questions to ask when using a non GAAP measure. Retirado de http:// www.iasplus.com/en/publications/us/heads up/2016/issue 10.

Deloitte (2016b). IFRS on Focus: alternative performance measures: a practical guide. Retirado de http:// www.iasplus.com/en/publications/global/other/apm.

Deloitte (2017). Thinking allowed non GAAP and alternative performance measures. Retirado de https://www. iasplus.com/en/publications/global/thinking allowed/2017/non gaap alternative performance measures.

Deloitte (2019). A roadmap to non GAAP financial measures. Retirado de https://www2.deloitte.com/us/ en/pages/audit/articles/a roadmap to non gaap financial measures.html.

Doyle, J. T., Lundholm, R. J., \& Soliman, M. T. (2003). The predictive value of expenses excluded from pro forma earnings. Review of Accounting Studies, 8(2 3), pp. 145 174. doi: 10.1023/A:1024472210359.

Doyle, J. T., Jennings, J. N., \& Soliman, M. T. (2013). Do managers define non GAAP earnings to meet or beat analyst forecasts?. Journal of Accounting and Economics, 56(1), pp. 40 56. doi: 10.1016/j. jacceco.2013.03.002.

European Securities and Market Authority (2015). ESMA guidelines on alternative performance measures. Retirado de https://www.esma.europa.eu/sites/default/files/library/2015/10/2015 esma 1415en.pdf.

Financial Reporting Council (2013). Feedback statement thinking about disclosures in a broader context. Retirado de https://www.frc.org.uk/Our Work/Publications/Accounting and Reporting Policy/ Thinking about disclosures in a broader contex/Feedback Statement/Feedback Statement Thinking about disclosures in a.aspx.

Frezatti, F., \& Aguiar, A. B. de. (2007). EBITDA: possíveis impactos sobre o gerenciamento das empresas. Revista Universo Contábil, 3(3), pp. 07 24. doi: http://dx.doi.org/10.4270/ruc.20073.

Graham, J., Harvey, C., \& Rajgopal, S. (2005). The economic implications of corporate financial reporting. Journal of Accounting and Economics, 40(1 3), pp. 3 73. doi: 10.1016/j.jacceco.2005.01.002.

Guest, N. M., Kothari, S. P., \& Pozen, R. (2019). High non GAAP earnings predict abnormally high CEO pay. doi:10.2139/ssrn.3030953. Retirado de: https://www.semanticscholar. org/paper/High Non GAAP Earnings Predict Abnormally High CEO Guest Kothari/ f0457657136b23cb7fff3d6a7789e1137123f402.

Heflin, F., \& Hsu, C. (2008). The impact of the SEC's regulation of non GAAP disclosures. Journal of Accounting and Economics, 46(2 3), pp. 349 365. doi: 10.2139/ssrn.494882.

International Accounting Standards Board (n.d.a). Primary Financial Statements About. Retirado de https://www.ifrs.org/projects/work plan/primary financial statements/\#about.

International Accounting Standards Board (n.d.b). Primary Financial Statements Project History. Retirado de https://www.ifrs.org/projects/work plan/primary financial statements/\#project history. 
International Accounting Standards Board (2011). Use of underlying earnings and non GAAP measures. Retirado de http://www.ifrs.org/Meetings/MeetingDocs/Advisory\%20Council/2011/June/20th\%20 and\%2021st/AC 0611 AP6.pdf.

International Accounting Standards Board (2018). Primary Financial Statements Supporting material. Retirado de https://www.ifrs.org//media/project/primary financial statements/supporting materials/pfs project overview sept 2018.pdf.

International Accounting Standards Board (2019). Primary Financial Statements project a game changer in financial reporting?. Retirado de https://www.ifrs.org/news and events/2019/03/hans speech pfs a game changer in financial reporting/.

International Federation of Accountants (2014). Developing and reporting supplementary financial measures Definition, principles and disclosures. Retirado de https://www.ifac.org/publications resources/ developing and reporting supplementary financial measures definition principl.

International Organization of Securities Commissions (2016). Statement on non GAAP financial measures. Retirado de https://www.iosco.org/library/pubdocs/pdf/IOSCOPD532.pdf.

Isidro, H., \& Marques, A. (2013). The effects of compensation and board quality on non gaap reporting decisions. The International Journal of Accounting, 48(3), pp. 289 317. doi: 10.1016/j. intacc.2013.07.004.

Iudícibus, S. de., \& Lopes, A. B. (2004). Teoria avançada da contabilidade. São Paulo: Atlas.

Johnson, A., Percy, M., Stevenson Clarke, P., \& Cameron, P. (2014). The impact of the disclosure of non GAAP earnings in Australian annual reports on non sophisticated users. Australian Accounting Review, 24(3), pp. 207 217. doi: 10.1111/auar.12034.

Lougee, B. A., \& Marquardt, C. A. (2004). Earnings informativeness and strategic disclosure: an empirical examination of 'pro forma' earnings. The Accounting Review, 79(3), pp. 769 795. doi: 10.2308/ accr.2004.79.3.769.

Macedo, M. A. S., Machado, M. R., Murcia, F. D., \& Machado, M. A. V. (2012). Análise da relevância do EBITDA versus fluxo de caixa operacional no mercado brasileiro de capitais. Advances in Scientific and Applied Accounting, 5(1), pp. 99 130. doi: 10.14392/ASAA/2012050105.

Malone, L., Tarca, A., \& Wee, M. (2016). IFRS non GAAP earnings disclosures and fair value measurement. Accounting \& Finance, 56(1), pp. 59 97. doi: 10.1111/acfi.12204.

Maragno, L. M. D., Borba, J. A., \& Fey, V. A. (2014). Como as empresas mais negociadas no BM\&FBOVESPA divulgam o EBITDA?. Revista de Contabilidade do Mestrado em Ciências Contábeis da UERJ, 19(1), pp. 58 79. doi: 10.12979/8194.

Marques, A. (2010). Disclosure strategies among S\&P 500 firms: evidence on the disclosure of non GAAP financial measures and financial statements in earnings press releases. The British Accounting Review, 42(2), pp. 119 131. doi: 10.1016/j.bar.2010.02.004.

Marques, A. (2017). Non GAAP earnings: international overview and suggestions for research. Meditari Accountancy Research, 25(3), pp. 318 335. doi: 10.1108/MEDAR 0420170140.

Matos, E. B. S., \& Murcia, F. D. (2019). IFRS 16: uma visão contábil prática e crítica da nova norma de leasing sob a ótica das arrendatárias. Revista Brasileira de Contabilidade, 51(238), pp. 50 65. doi: $10.17648 /$ rbc vol0n238 1887.

Miller, J. S. (2009). Opportunistic Disclosures of Earnings Forecasts and Non GAAP Earnings Measures. Journal of Business Ethics, 89(1), pp. 03 10. doi: 10.1007/s10551 00899030. 
Momose, C. I. (2009). EBITDA: sua utilização e interpretação no contexto da qualidade das informações contábeis na visão dos analistas de mercado de capitais (Dissertação de Mestrado, Pontifícia Universidade Católica de São Paulo, São Paulo). Retirado de https://tede2.pucsp.br/handle/handle/1726.

Nichols, N., Gray, S., \& Street, D. (2005). Pro Forma Adjustments to GAAP Earnings: Bias, Materiality, and SEC Action. Research in Accounting Regulation, 18, pp. 29 52. doi: 10.1016/S1052 0457(05)18002 3.

Oliveira, N. L. (2018). Efeito da divulgação de relatórios GAAP e não GAAP sobre o valor das ações no mercado brasileiro de capitais (Dissertação de Mestrado, Universidade Brasília, Brasília). Retirado de http://bdtd.ibict.br/vufind/Record/UNB_cb528f5a015cee74a13624f9df16eed4.

PricewaterhouseCoopers (2014). Point of view: non GAAP financial measures Enhancing their usefulness. Retirado de https://www.pwc.com/us/en/cfodirect/assets/pdf/point of view non gaap financial measures.pdf.

Securities and Exchance Comission SEC (2003). Final rule: conditions for use of non GAAP financial measures. Release No. 33 8176, 34 47226; FR 65. Retirado de https://www.sec.gov/rules/final/33 8176.htm.

Young, S. (2014). The drivers, consequences and policy implications of non GAAP earnings reporting. Accounting and Business Research, 44(4), pp. 444 465, doi: 10.1080/00014788.2014.900952.

Webber, N. S., Nichols, D. N., \& Street, D. (2013). Non GAAP adjustments to net income appearing in the earnings releases of the S\&P 100: An analysis of frequency of occurrence, materiality and rationale. Research in Accouting Regulation, 25(2), pp. 236 251. doi: 10.1016/j.racreg.2013.08.011 